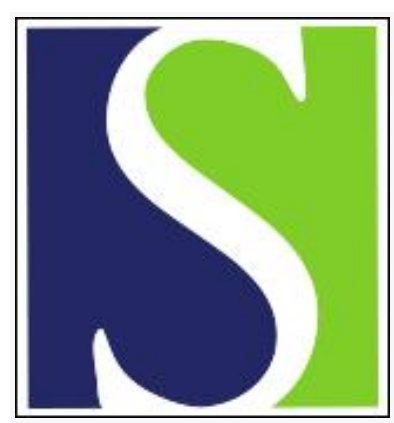

Scand J Work Environ Health 2001;27(2):140-145

https://doi.org/10.5271/sjweh.601

Issue date: Apr 2001

Effects of electric field reduction in visual display units on skin symptoms

by Skulberg KR, Skyberg K, Eduard W, Goffeng LO, Vistnes Al, Levy F, Kjuus $\mathrm{H}$

Affiliation: National Institute of Occupational Health, PO Box 8149 Dep, N-0033 Oslo, Norway. rskulber@online.no

Refers to the following text of the Journal: 1995;21(5):335-344

Key terms: electric field reduction; electromagnetic fields; intervention study; office environment; particle; psychological behavior test; skin symptom; static electric field; visual display unit

This article in PubMed: www.ncbi.nlm.nih.gov/pubmed/11409597

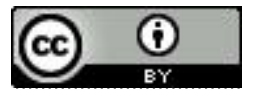




\title{
Effects of electric field reduction in visual display units on skin symptoms
}

\author{
by Knut R Skulberg, MD, ${ }^{1}$ Knut Skyberg, MD, ${ }^{1}$ Wijnand Eduard, PhD, ${ }^{1}$ Lars Ole Goffeng, DPsych, ${ }^{1}$ \\ Arnt I Vistnes, PhD, ${ }^{2}$ Finn Levy, MD, ${ }^{3}$ Helge Kjuus, $M D^{1}$
}

\begin{abstract}
Skulberg KR, Skyberg K, Eduard W, Goffeng LO, Vistnes Al, Levy F, Kjuus H. Effects of electric field reduction in visual display units on skin symptoms. Scand J Work Environ Health 2001;27(2):140—145.
\end{abstract}

\begin{abstract}
Objectives This study investigated the facial skin complaints of office workers before and after the static electric fields of a visual display unit were reduced.

Methods On the basis of a screening survey of 4556 office workers in 11 companies, 120 of 227 subjects reporting facial skin complaints were randomly selected to this double blind intervention study. Antistatic measures were used to reduce the static electric fields of the visual display unit in the intervention group but not in the control group, which worked with a visual display unit resembling that of the intervention group. Electric fields, dust concentration, health complaints, and psychological behavior tests were recorded before and after the intervention.

Results The intervention group reported statistically significantly fewer facial skin complaints than the control group. In the intervention group, among those with an office dust concentration of $>58 \mu \mathrm{g} / \mathrm{m}^{3}$, a median reduction of 1.5 skin index points (scale $0-8$ ) was achieved, whereas there was no change in the control group. In the regression model "group category" was still a significant variable after control for background factors. In addition, further linear regression analyses indicated that several static electric field parameters were predictors of the skin complaint reduction.

Conclusions This field trial indicates that removing static electric fields from visual display units can probably help reduce the facial skin complaints of workers in offices with high dust concentrations.
\end{abstract}

Key terms electromagnetic fields, intervention study, office environment, particles, psychological behavior tests, static electric fields.

The first cases of facial skin complaints among users of a visual display unit (VDU) were described in the early 1980s $(1,2)$. The case reports were followed by experimental and epidemiologic studies (3-7). Some of the latter have reported an exposure-response relationship between the duration of VDU work and the occurrence of self-reported skin complaints $(6,7)$. Hypotheses on the etiology of facial skin symptoms have been psychological stress during VDU work $(8,9)$, low relative humidity (10), and alternating electromagnetic and electrostatic fields in front of the VDU $(11,12)$.

Our study was based on the hypothesis that the motion of charged particles is affected by the static electric fields between the VDU and the operator. Particles can be attracted either to the operator or the VDU, depending on the particle charge and the field character- istics. Such an attraction may give rise to an increased dust deposition on the face of the operator, which in turn produces facial skin symptoms (13). Schneider et al (14) found that electric fields and particle charges were major determinants of the deposition of particles with a diameter of $\sim 1 \mu \mathrm{m}$. The electrostatic field hypothesis has been tested by Swanbeck \& Bleeker (15) in a double blind experimental study. No difference in facial skin symptoms was found when the participants worked in front of a VDU with or without electrostatic fields. In a cross-sectional study by Bergquist \& Wahlberg (10), no association was found between current electromagnetic field levels and skin disease. In a crosssectional study by Sandström et al (11) higher background electric fields were found among cases with skin symptoms than among the referents. However,

$1 \quad$ National Institute of Occupational Health, Oslo, Norway.

2 Institute of Physics, University of Oslo, Oslo, Norway.

3 Ullevål University Hospital, Oslo, Norway.

Reprint requests to: Dr Knut R Skulberg, National Institute of Occupational Health, PO Box 8149 Dep, N-0033 Oslo, Norway. [E-mail: rskulber@online.no] 
these authors found no association between the electrostatic field in front of the VDU and skin symptoms. Sundell et al (16) found that floor cleaning twice a week, some types of lighting, and some types of foundation were associated with skin problems among VDU workers. One experimental field study gave some support to the hypothesis that skin symptoms were caused by electric fields, but it was not conclusive as to whether static or alternating fields were responsible (12). Thus there was a need for further intervention studies addressing the interaction between static electric fields and dust.

\section{Subjects and methods}

\section{Study design and population}

An experimental intervention study design with an intervention group and a control group was chosen. Both the investigators and the participants were blinded to the group assignation of the participants. A screening questionnaire was distributed to office workers in 11 companies, constituting the study base. The participants for the intervention trial were selected, on the basis of reported skin symptoms, from the 4556 persons returning the completed questionnaire. The inclusion criteria were skin symptom indices $\geq 4$ on a $0-8$ scale constructed from 4 questions about facial skin (dry, red, or itching or burning sensation of facial skin; $0=$ no symptoms, 1 = sometimes symptoms, 2 = often symptoms). The participants had to work at least 4 hours daily at a VDU. The following levels were used for the calculation of statistical power: (i) $80 \%$ statistical power to detect an 0.5 -point change in the skin symptom index (26 participants) and (ii) $95 \%$ statistical power to detect an 0.5-point change (58 participants) (2-sided test). In all 11 companies $\sim 15 \%$ had a skin symptom index score of $\geq 4$. The 4 companies with the largest number of employees and respondents were selected for the intervention. There were 229 persons meeting the criteria for inclusion in these companies. Of these 229 persons, 120 were randomly selected and asked to participate. The participants had their own offices and were not to be out of work more than 3 days during the intervention period. If a person could not participate, another one was randomly selected. The intervention and control groups were selected from the 120 persons with the use of block matching for gender, age, and asthma or rhinitis. There was an equal distribution for gender (45\% men and 55\% women), age (mean 39 years), asthma or rhinitis $(42 \%)$, smokers $(16 \%)$, and VDU work (mean 6 hours/day) in the 2 groups. Three persons originally included were unable to take part in the followup, 2 having moved to another office and 1 having gone on a long work-related trip. Thus 117 persons were fol- lowed in the trial (59 persons in the control group and 58 persons in the intervention group).

The intervention group received the following treatment: the top, the front and the sides of their VDU were treated with an antistatic ionic liquid, an antistatic mat was placed on the floor, and a conducting strip was fastened to the edge of the keyboard. The VDU surface, the keyboard, and the antistatic mat were grounded. The control group received a treatment with a similar appearance, except that the liquid had no electrical conducting properties and the grounding "cables" had no conducting wires.

\section{Exposure characterization}

Electric fields were measured around the VDU at the workplace before and after the intervention. The static electric fields $(10$ and $50 \mathrm{~cm}$ ) were measured by a JCI 122 field mill (John Chubb Instrumentation, Cheltham, England). The static electric field at $10 \mathrm{~cm}$ was measured according to the MPR II/TCO92 procedure (17), adapted for a real workplace. The time-variable electric fields, extremely low frequency (ELF, 50-2000 Hz) and very low frequency (VLF, 2-400 kHz) were measured by an EMM4 Guy probe (Radians Innova, Göteborg, Sweden).

The electric-field results were analyzed in 2 ways. The absolute values of the measurements were used as a parameter, and another "change in field" parameter $[\Delta(\mathrm{E})]$ was constructed (prior to the analysis of the health data) from the relative and the absolute change in the electric field:

$$
\Delta(\mathrm{E})=k \cdot \sqrt[4]{\left|E_{1}\right|+\left|E_{2}\right|} \cdot \frac{\left|E_{2}\right|-\left|E_{1}\right|}{0.5 \cdot\left(\left|E_{1}\right|+\left|E_{2}\right|+C\right)},
$$

where: $\mathrm{k}=$ an arbitrary scaling factor, $\mathrm{k}=0.5$ for "hot spots", otherwise $\mathrm{k}=1$

$\mathrm{E}_{1}=$ the electric field before treatment, in $\mathrm{V} / \mathrm{m}$ (ELF, VLF) or $\mathrm{kV} / \mathrm{m}$ (static fields)

$\mathrm{E}_{2}=$ the electric field after treatment, in $\mathrm{V} / \mathrm{m}$ (ELF, VLF) or $\mathrm{kV} / \mathrm{m}$ (static fields)

$\mathrm{C}=\mathrm{a}$ value corresponding to a very weak electric field.

The local static electric field was determined by placing the field mill probe about $1 \mathrm{~cm}$ from the surface ( 45 positions) of the front, the top and the right and left sides of the VDU screen or cabinet. "Hot spot" parameters have been given as the largest electrostatic field found ("maximum value") and as the mean value of the 7 largest of the 45 measurements ("representative high value"). All the measurements referred to in this report were carried out with grounded probes. 
Only 15 of 112 units had a considerable static electric field in the front (surface potential more than $500 \mathrm{~V}$ ) when measured according to the MPR II/TCO92 procedure. The units with high static electric fields were older than the others (up to 10 years of age). However, moderate or strong "hot spots" (apparent surface potential more than $500 \mathrm{~V}$ ) were present on 70 of the 112 units, including relatively new screens. The electrostatic fields were lower in the intervention group than in the control group (table 1). Except for ELF $30 \mathrm{~cm}$ from the surface, alternating electric fields were not affected by the intervention.

Dust concentrations were measured by a GRIMM (type 1.105, Labortechnic GmbH, Ainring, Germany) size-selective optical particle counter (18) before and after the intervention. The particle counter was placed between the worker and the VDU. Dust was measured for 5 minutes. During the measurements the participants worked in front of the VDU, the door and windows were closed, and the hygienist had left the office.

Dust measurements were performed in 87 offices before the intervention (median dust concentration being $58 \mu \mathrm{g} / \mathrm{m}^{3}$ ). Measurements taken both before and after the treatment were available for 71 offices. There was some reduction in the dust concentration after the treatment, but no statistically significant difference between the intervention and the control group was found (median values of $-5 \mu \mathrm{g} / \mathrm{m}^{3}$ versus $-10 \mu \mathrm{g} / \mathrm{m}^{3}$ ).

\section{Methods for monitoring health effects}

Health indicators were measured before, 2 weeks after, and 4 weeks after the intervention. The measurements were done in the afternoon on Wednesdays, Thursdays, or Fridays. The participants were examined at the same time of day and by the same examiner. The tests were carried out in the offices of the occupational health services of the companies.

Self-reported skin and mucous membrane symptoms and general symptoms were collected by a questionnaire, modified from the form used in Sweden in extensive indoor-air surveys (19). Three symptom indices were constructed from the questionnaire in the following way. Each question was given a value according to the response categories ( 0 for never, 1 for sometimes and 2 for often symptoms). The value from each question was summarized in a skin symptom index (dry, red, or itching or burning sensation of facial skin), a mucous membrane symptom index (irritation of nose, throat, eyes or cough), and a general symptom index (fatigue, heavy-headed, headache, nausea, or concentration problems). The possible values ranged from 0 to 8 , except for the general index, which had a range of 0 to 10 . The questions on "hay fever" and "asthmatic symptoms" in the questionnaire did not fully cover the concept of atopy. Therefore, the term "asthma or rhinitis" was used for those answering "yes" to one or both questions as an indicator of atopy.

Four computerized psychological behavior tests of the Neurobehavioral Evaluation System (NES) 2 were selected (20), measuring simple and choice reaction times, and a symbol-digit substitution task. The total test time was approximately 30 minutes, and the same computer was used in all the tests before and after the treatment.

\section{Statistics}

The difference between the health indices before and after the treatment was calculated for both the intervention and the control groups and compared. Some variables

Table 1. Electric field measurements and "change in field parameter". $(E L F=$ extremely low frequency, VLF = very low frequency)

\begin{tabular}{|c|c|c|c|c|c|c|c|c|c|c|c|}
\hline & \multicolumn{5}{|c|}{ Control group } & \multicolumn{5}{|c|}{ Intervention group } & \multirow{3}{*}{ P-value ${ }^{b}$} \\
\hline & \multirow{2}{*}{$\begin{array}{l}\text { Before } \\
\text { (median) }\end{array}$} & \multirow{2}{*}{$\begin{array}{l}\text { After } \\
\text { (median) }\end{array}$} & \multicolumn{3}{|l|}{ Change } & \multirow{2}{*}{$\begin{array}{l}\text { Before } \\
\text { (median) }\end{array}$} & \multirow{2}{*}{$\begin{array}{l}\text { After } \\
\text { (median) }\end{array}$} & \multicolumn{3}{|l|}{ Change } & \\
\hline & & & Median & $\begin{array}{l}\text { 25th } \\
\text { \%ile }\end{array}$ & $\begin{array}{l}\text { 75th } \\
\% \text { ile }\end{array}$ & & & Median & $\begin{array}{l}25 \text { th } \\
\% \text { ile }\end{array}$ & $\begin{array}{l}\text { 75th } \\
\% \text { ile }\end{array}$ & \\
\hline \multicolumn{12}{|l|}{ Static electric field } \\
\hline $\begin{array}{l}10 \mathrm{~cm} \\
50 \mathrm{~cm}\end{array}$ & $\begin{array}{r}0.00 \\
-0.05\end{array}$ & $\begin{array}{l}0.14 \\
0.23\end{array}$ & $\begin{array}{l}0.04 \\
0.03\end{array}$ & $\begin{array}{l}-0.17 \\
-0.27\end{array}$ & $\begin{array}{l}0.75 \\
0.61\end{array}$ & $\begin{array}{r}-0.05 \\
0.00\end{array}$ & $\begin{array}{l}0.00 \\
0.00\end{array}$ & $\begin{array}{l}-0.27 \\
-0.19\end{array}$ & $\begin{array}{l}-0.69 \\
-0.62\end{array}$ & $\begin{array}{l}0.00 \\
0.00\end{array}$ & $\begin{array}{l}0.000 \\
0.001\end{array}$ \\
\hline \multicolumn{12}{|l|}{ Hot spot } \\
\hline $\begin{array}{l}\text { Maximum value } \\
\text { Representative value }\end{array}$ & $\begin{array}{r}95 \\
6\end{array}$ & $\begin{array}{l}91 \\
16\end{array}$ & $\begin{array}{l}0.26 \\
0.39\end{array}$ & $\begin{array}{l}0.04 \\
0.04\end{array}$ & $\begin{array}{l}0.88 \\
0.88\end{array}$ & $\begin{array}{l}11 \\
11\end{array}$ & $\begin{array}{l}0 \\
0\end{array}$ & $\begin{array}{l}-0.95 \\
-0.95\end{array}$ & $\begin{array}{l}-2.26 \\
-2.26\end{array}$ & $\begin{array}{l}-0.19 \\
-0.19\end{array}$ & $\begin{array}{l}0.000 \\
0.000\end{array}$ \\
\hline \multicolumn{12}{|l|}{ ELF field } \\
\hline $\begin{array}{l}30 \mathrm{~cm} \\
50 \mathrm{~cm}\end{array}$ & $\begin{array}{l}32.0 \\
18.6\end{array}$ & $\begin{array}{l}31.5 \\
17.0\end{array}$ & $\begin{array}{r}0.04 \\
-0.12\end{array}$ & $\begin{array}{l}-0.91 \\
-0.87\end{array}$ & $\begin{array}{l}0.62 \\
0.49\end{array}$ & $\begin{array}{l}27.3 \\
16.3\end{array}$ & $\begin{array}{l}17.6 \\
12.8\end{array}$ & $\begin{array}{l}-0.85 \\
-0.46\end{array}$ & $\begin{array}{l}-1.50 \\
-1.28\end{array}$ & $\begin{array}{r}-0.18 \\
0.30\end{array}$ & $\begin{array}{l}0.002 \\
0.29\end{array}$ \\
\hline \multicolumn{12}{|l|}{ VLF field } \\
\hline $\begin{array}{l}30 \mathrm{~cm} \\
50 \mathrm{~cm}\end{array}$ & $\begin{array}{l}2.26 \\
0.86\end{array}$ & $\begin{array}{l}2.42 \\
0.84\end{array}$ & $\begin{array}{r}-2 \\
-10\end{array}$ & $\begin{array}{l}-10 \\
-29\end{array}$ & $\begin{array}{l}0 \\
2\end{array}$ & $\begin{array}{l}3.00 \\
1.03\end{array}$ & $\begin{array}{l}2.75 \\
0.94\end{array}$ & $\begin{array}{r}0 \\
-5\end{array}$ & $\begin{array}{r}-7 \\
-26\end{array}$ & $\begin{array}{l}2 \\
7\end{array}$ & $\begin{array}{l}0.17 \\
0.36\end{array}$ \\
\hline
\end{tabular}

a Static electric fields and hot spots are given in kilovolts per meter, and the others (time variable) are in volts per meter.

${ }^{b}$ Mann-Whitney U test, two sided; intervention group versus control group. 
showed a nonnormal distribution, even after logarithmic transformation. Therefore, a 2-sided Mann-Whitney U test was used for all the comparisons of the 2 groups. Analyses of the skin symptom index were also performed with a stratification for dust level. Using the median dust level from dust measurements obtained before the intervention, we divided the participants into 2 groups, a "low-dust group" and a "high-dust group". The Pearson bivariate correlation coefficient was calculated for the association between the psychological test results and the general symptom index.

The outcomes for the symptom index variables showed a near-normal distribution. Therefore, multivariate analyses using linear regression could be used. All the independent variables were entered into the analysis (asthma or rhinitis, age, gender, daily time in front of a VDU, current smoking status, and group category or change in electric field). The residuals were inspected for the assessment of the model fit. The analyses were also stratified for "low" and "high" dust level.

\section{Results}

\section{Single and multivariate analyses with the group category variable}

A reduction in general symptoms was observed after the treatment in both the control (median index value reduced from 4.0 to 3.5 on a 10-point scale) and the intervention (median reduced from 4.0 to 3.5 ) groups. A test of the difference between the groups showed a Pvalue of 0.53 . We found the same trend for the mucous membrane symptoms (especially eye irritation symptoms). The median index value decreased from 3.0 to 2.5 on an 8-point scale in the control group and from 3.0 to 2.25 in the intervention group, and the difference between the groups was not statistically significant (Pvalue $=0.99$ ).
There was a larger skin symptom index reduction in the intervention group than in the control group (table 2). When stratification by dust level was used, a reduction in the skin symptom index was found in the high-dust group only, while no difference was observed in the low-dust group. The median of the skin symptom index for the participants with high dust exposure in the intervention group decreased from 4.0 to 3.0, but there was no reduction in the control group.

The psychological behavior tests revealed no statistically significant difference in the change between the 2 groups. Both groups performed the tests faster after the treatment. The number of errors was very low in both groups, and the performance speed early in the tests did not differ from the speed late in the tests. However, a statistically significant correlation was found between the most complex choice-reaction-time test and the general symptom index.

For the outcomes "general" and "mucous membrane" symptoms, group category was not a significant predictor in the regression analysis. For "skin symptoms", however, regardless of the dust level in the office, the group category was a nearly statistically significant independent variable (table 3). When the regression analyses were conducted with stratification for dust level, the group category was a statistically significant predictor in the high-dust group.

\section{Multivariate analyses with the change in electric fields}

Additional linear regression analyses conducted for the change in static electric fields instead of group category showed a pattern similar to that revealed in the multivariate analyses with group category (intervention or control) as the independent variable (table 3 ). The reduction in static electric fields was a stronger predictor for reduced skin symptoms than group category was. Other statistically significant variables in the model were age and gender.

Table 2. Skin symptom index development for all the participants and for the groups when stratified by dust level.

\begin{tabular}{|c|c|c|c|c|c|c|c|c|c|c|c|}
\hline & \multicolumn{5}{|c|}{ Control group } & \multicolumn{5}{|c|}{ Intervention group } & \multirow{3}{*}{ P-value } \\
\hline & \multirow{2}{*}{$\begin{array}{l}\text { Before } \\
\text { (median) }\end{array}$} & \multirow{2}{*}{$\begin{array}{l}\text { After } \\
\text { (median) }\end{array}$} & \multicolumn{3}{|l|}{ Change } & \multirow{2}{*}{$\begin{array}{l}\text { Before } \\
\text { (median) }\end{array}$} & \multirow{2}{*}{$\begin{array}{l}\text { After } \\
\text { (median) }\end{array}$} & \multicolumn{3}{|l|}{ Change } & \\
\hline & & & Median & $\begin{array}{l}\text { 25th } \\
\% \text { ile }\end{array}$ & $\begin{array}{l}\text { 75th } \\
\% \text { ile }\end{array}$ & & & Median & $\begin{array}{l}\text { 25th } \\
\% \text { ile }\end{array}$ & $\begin{array}{l}75 \text { th } \\
\% \text { ile }\end{array}$ & \\
\hline $\begin{array}{l}\text { Low-dust group } \\
(\mathrm{N}=44)\end{array}$ & 4.5 & 4.0 & -0.5 & -2.0 & 0.5 & 4.0 & 4.0 & -1.0 & -1.0 & 0.5 & 0.82 \\
\hline $\begin{array}{l}\text { High-dust groupc } \\
(\mathrm{N}=43)\end{array}$ & 4.0 & 4.0 & 0.0 & -1.0 & 0.5 & 4.0 & 3.0 & -1.5 & -2.0 & -0.5 & 0.02 \\
\hline Total $(\mathrm{N}=117)$ & 4.0 & 4.0 & 0.0 & -1.0 & 0.5 & 4.0 & 3.5 & -1.0 & -1.5 & 0.0 & 0.04 \\
\hline
\end{tabular}

a Mann-Whitney U test, two-sided; intervention group versus control group.

${ }^{b}$ Dust concentration at or below the median value $\left(58 \mu \mathrm{g} / \mathrm{m}^{3}\right)$.

c Dust concentration above the median value $\left(58 \mu \mathrm{g} / \mathrm{m}^{3}\right)$ 
Table 3. Skin symptom improvement in relation to the group category or the reduction in static electric fields. Linear regression analysis for all the participants and stratified according to dust level (statistically significant variables in italics). (95\% Cl $=95 \%$ confidence interval)

\begin{tabular}{|c|c|c|c|}
\hline & Adjusted $\mathrm{R}^{2}$ of model a & Regression coefficient & $95 \% \mathrm{Cl}$ of regression coefficient \\
\hline \multicolumn{4}{|l|}{ Group category } \\
\hline All participants (N=117) & 0.27 & -0.40 & $-0.84-0.04$ \\
\hline Low-dust group ${ }^{b}(\mathrm{~N}=44)$ & 0.05 & 0.00 & $-0.92-0.91$ \\
\hline High-dust groupc $(\mathrm{N}=43)$ & 0.50 & -0.73 & $-1.40--0.05$ \\
\hline \multicolumn{4}{|c|}{ Reduction of static electric fields } \\
\hline \multicolumn{4}{|l|}{ All participants (N=117) } \\
\hline \multicolumn{4}{|l|}{ Static electric fields } \\
\hline $10 \mathrm{~cm}$ & 0.30 & -0.15 & $-0.29-0.00$ \\
\hline $50 \mathrm{~cm}$ & 0.32 & -0.34 & $-0.61--0.07$ \\
\hline \multicolumn{4}{|l|}{ Hot spots } \\
\hline Maximum value & 0.31 & -0.13 & $-0.24--0.02$ \\
\hline Representative value & 0.30 & -0.15 & $-0.31-0.01$ \\
\hline \multicolumn{4}{|l|}{ Low-dust group $(\mathrm{N}=44)$} \\
\hline \multicolumn{4}{|l|}{ Static electric fields } \\
\hline $10 \mathrm{~cm}$ & 0.03 & 0.01 & $-0.26-0.29$ \\
\hline $50 \mathrm{~cm}$ & 0.04 & -0.16 & $-0.67-0.34$ \\
\hline \multicolumn{4}{|l|}{ Hot spots } \\
\hline Maximum value & 0.07 & -0.13 & $-0.36-0.10$ \\
\hline Representative value & 0.03 & -0.06 & $-0.38-0.24$ \\
\hline \multicolumn{4}{|l|}{ High-dust group $(\mathrm{N}=43)$} \\
\hline \multicolumn{4}{|l|}{ Static electric fields } \\
\hline $10 \mathrm{~cm}$ & 0.66 & -0.25 & $-0.42--0.08$ \\
\hline $50 \mathrm{~cm}$ & 0.64 & -0.48 & $-0.85--0.11$ \\
\hline \multicolumn{4}{|l|}{ Hot spots } \\
\hline Maximum value & 0.68 & -0.23 & $-0.37--0.09$ \\
\hline Representative value & 0.70 & -0.47 & $-0.73--0.22$ \\
\hline
\end{tabular}

a The following variables were entered into all the models: gender, age, asthma-rhinitis, smoking, daily time in front of a video display unit and group category or change in static electric fields.

${ }^{b}$ Dust concentration at or below the median value $\left(58 \mu \mathrm{g} / \mathrm{m}^{3}\right)$.

c Dust concentration above the median value $\left(58 \mu \mathrm{g} / \mathrm{m}^{3}\right)$.

The results were obtained using the "change in field parameter" $(\Delta \mathrm{E})$. However, the results proved to be similar when the change in the absolute electric field values was used instead of $\Delta \mathrm{E}$. Stratified analyses based on dust concentrations of $<5 \mu \mathrm{m}$ particles instead of all measured particle sizes also showed similar results. None of the alternating electric field indicators were predictors of skin symptom improvement.

\section{Discussion}

\section{Possible causes of skin symptoms related to visual display units}

Our findings provide some support for the hypothesis that exposure to static electric fields and dust may interact to cause skin symptoms among VDU users. However, the observation does not exclude additional causal factors, especially as there was still a nonnegligible degree of symptoms after the intervention. Stenberg et al (7) demonstrated an effect of psychosocial load for the occurrence of skin symptoms among VDU users. Berg et al (9) found higher levels of stress hormones in the blood of VDU users. The amount of stress hormones was highly correlated with the severity of skin symptoms.

According to Schneider et al (14) only small particles $(\leq 1 \mu \mathrm{m})$ are influenced by static electric fields. It was not possible to verify this assumption in our study, as we observed a high correlation between the concentration of $\leq 5 \mu \mathrm{m}$ particles and the total dust concentration. This study showed reduced skin symptoms after intervention among participants in offices with a high dust concentration. In a previous experimental study (15) working in front of a VDU had no effect on skin symptoms. The difference may be due to relatively low dust levels in the latter study.

\section{Static electric fields of visual display units or personal electric charge as the causative factor}

In this study the intervention involved both the treatment of the VDU and the introduction of an antistatic mat in order to reduce the static electric charge of the person. One might argue that the effect observed was due to the reduced static charge of the person rather than the reduction in static electric field from the VDU. 
There is no reason to believe that there is a doseresponse relationship between the electrostatic charge of a person and the static electric field from a VDU. Thus, since multivariate linear regression pinpoints static electric fields from the VDU as the most important factor for reduced skin effect, the results indicate that the electrostatic charge of the person alone does not explain the symptom improvement. An observation from the analyses points in the same direction. The ELF electric field $30 \mathrm{~cm}$ in front of the VDU was statistically significantly reduced by the intervention (table 1), but it failed to be a factor of importance in explaining the reduction in skin symptoms (table 3 ).

It is well known that humans may be charged to several thousand volts (up to about $20000 \mathrm{~V}$ ). However, Martinsen (21) showed that the mean value for the static electric charge is much lower than the peak values. A "hot spot" on a VDU, on the other hand, has a relatively constant, rather high potential. Thus, for persons working in front of a VDU with a substantial static electric field (like $70 \%$ of the participants in this study), the electric field between the VDU and the person will be dominated by the VDU field, rather than the person's electrostatic charge.

\section{Concluding remarks}

This study provides some support for the hypothesis that skin symptoms can be relieved by reducing the static electric fields of a VDU in offices with a high dust concentration. Lowering the VDU static electric fields did not affect general or irritation symptoms. A reduction in the ELF field measured at $30 \mathrm{~cm}$ in front of the VDU was not followed by any symptom reduction.

\section{Acknowledgments}

This study was funded by the Norwegian Research Council and the Work Environment Fund of the Norwegian Confederation of Business and Industry.

We are grateful for the participation of the occupational health services, the employees, and the management at Alcatel, Norsk Hydro, Samvirke and Storebrand.

The study was approved by the regional medical ethics committee.

\section{References}

1. Lidén V, Rolfsen S. Video computer terminals and occupational dermatitis [letter]. Scand J Work Environ Health 1981;7:62-3.

2. Nilsen A. Facial rash in visual display unit operators. Contact Dermatitis 1982;8:25-8.
3. Rycroft RJG, Calnan CD. Facial rashes among visual display unit (VDU) operators. In: Pearce BG, editor. Health hazards of VDTs? New York (NY): John Wiley \& Sons, 1984:13-6.

4. Fischer AA. "Terminal" dermatitis due to computers (visual display units). Cutis 1986;37:153—4.

5. Stenberg B. Skin complaints in buildings with indoor climate problems. Environ Int 1989;15;81—4.

6. Berg M, Liden MD, Axelsen O. Facial skin complaints and work at visual display units: an epidemiological study of office employees. J Am Acad Dermatol 1990;22(4):621—5.

7. Stenberg B, Mild KH, Sandström M, Sundell J, Wall S. A prevalence study of the sick building syndrome (SBS) and facial skin symptoms in office workers. Indoor Air 1993; $3: 71-81$.

8. Lidén C, Wahlberg JE. Work with video display terminals among office employees, V: dermatologic factors. Scand J Work Environ Health 1985;11: 489—93.

9. Berg M, Arnetz BB, Lidén S, Eneroth P, Kallner A. Techno-stress. A psychophysiological study of employees with VDU-associated skin complaints J Occup Med 1992; 34(7):698-701.

10. Bergquist U, Wahlberg JE. Skin symptoms and disease during work with visual display terminals. Contact Dermatitis 1994;30:197-204.

11. Sandström M, Mild KH, Stenberg B, Wall S. Skin symptoms among VDT workers and electromagnetic fields - a case referent study. Indoor Air 1995;5:29-37.

12. Oftedal G, Vistnes AI, Rygge K. Skin symptoms after the reduction of electric fields from visual display units. Scand J Work Environ Health 1995;21:335-44.

13. Olsen CW. Electric fields enchanced aerosol exposure in visual display unit environments. Bergen: The Chr. Michelsen Institute, Department of Science and Technology, 1981: $1-40$.

14. Schneider T, Bohgard M, Gudmundsson A. A semiempirical model for particle deposition onto facial skin and eyes. Role of air-currents and electric fields. J Aerosol Sci 1994;25:583-93.

15. Swanbeck G, Bleeker T. Skin problems from visual display units. Provocation of skin symptoms under experimental condition. Acta Derm Venereol (Stockh) 1989;69:46-51.

16. Sundell J, Lindvall T, Stenberg B, Wall S. Sick building syndrome (SBS) in office workers and facial skin symptoms among VDT-workers in relation to building and room characteristics: two case-referent studies. Indoor Air 1994; suppl 2.

17. Swedac. Provningsmetoder för bildskärmar [Test methods for visual display units]. Stockholm: MPR, 1990:7.

18. Vincent JH. Aerosol science for industrial hygienists. New York (NY): Elsevier Science Inc, 1995:313.

19. Andersson K, Fagerlund I, Stridh G, Larsson B. The MMquestionnaires: a tool when solving indoor climate problems. Örebro: Örebro Medical Center Hospital, 1993.

20. Letz R. NES2 user's manual, version 4.6. Winchester (MA): Neurobehavioral Systems Inc, 1994.

21. Martinsen, ACT. Statisk personoppladning. Kontinuerlig registrering av personers statiske oppladning gjennom en arbeidsdag. [Static personal charge: a continuous registration of static personal charge during one workday] [dissertation]. Oslo: Department of Physics, University of Oslo, 1998.

Received for publication: 1 December 1999 